\title{
Mechanical Fatigue Analysis of AlN/SUS430/AlN Heterolayered Foils in Micromachined Devices
}

\author{
Qiu Zheng, ${ }^{*}$ Le Van Minh, Hung Hoang Nguyen, and Hiroki Kuwano** \\ New Industry Creation Hatchery Center, Tohoku University \\ 6-6-10 Aramaki-Aoba, Aoba-ku, Sendai, Miyagi 980-8579, Japan
}

(Received March 9, 2020; accepted April 15, 2020)

Keywords: flexible device, AlN/SUS430/AlN heterolayered foils, micromachined specimen, fatigue defects

The combination of piezoelectric aluminum nitride (AlN) films with flexible substrates made of stainless steel (SUS) foils has been applied in low-frequency and robust microdevices, especially in piezoelectric vibration energy harvesters (PVEHs). To find guides in the design of PVEHs, the fatigue properties of micromachined specimens fabricated using SUS430 foils and AlN/SUS430/AlN heterolayered foils were investigated in this work. In particular, the thickness dependence of AlN films on the fatigue behavior of AlN/SUS430/AlN heterolayered foils was investigated. AlN films with different thicknesses of 1 and $2 \mu \mathrm{m}$ were deposited on 50 - $\mu \mathrm{m}$-thick SUS430 substrates. The specimens for fatigue tests were prepared as cantilevers by microfabrication processes. First, Young's moduli were measured. Fatigue tests were subsequently conducted by resonant bending. The fatigue behavior is discussed in this paper on the basis of both the stress-number of cycle $(S-N)$ curves and the fatigue failures on the surfaces of the cantilevers. The fatigue limits of SUS430 $(50 \mu \mathrm{m})$, AlN $(1 \mu \mathrm{m}) /$ SUS430 $(50 \mu \mathrm{m}) / \mathrm{AlN}(1 \mu \mathrm{m})$, and AIN $(2 \mu \mathrm{m}) / \operatorname{SUS} 430(50 \mu \mathrm{m}) / \mathrm{AlN}(2 \mu \mathrm{m})$ were estimated to be 264, 291, and $368 \mathrm{MPa}$, respectively. The larger stiffness of the foils with a heterolayered AlN/SUS430/AlN structure indicated their larger fatigue limit than the SUS430 foil. Fatigue failure in the form of cracks was observed on the surface of SUS430 for AIN $(1 \mu \mathrm{m})$ /SUS430/ AlN $(1 \mu \mathrm{m})$ when vibrating at the maximum stress of $488 \mathrm{MPa}$ for $2.9 \times 10^{7}$ cycles. Surface defects of intrusions and slip bands rather than cracks were observed on the SUS430 substrate for the heterolayered AlN $(2 \mu \mathrm{m}) / \operatorname{SUS} 430 / \mathrm{AlN}(2 \mu \mathrm{m})$ structure when vibrated at the maximum stress of $605 \mathrm{MPa}$ for $2.9 \times 10^{7}$ cycles, resulting in its higher fatigue limit than that of $(1 \mu \mathrm{m}) / \mathrm{SUS} 430 / \mathrm{AlN}(1 \mu \mathrm{m})$. No surface defects on AlN films were observed after undergoing the aforementioned long-cycle vibration.

\section{Introduction}

Micro-piezoelectric vibration energy harvesters (PVEHs) have prospective use as the power source in microelectromechanical systems. ${ }^{(1,2)}$ They can generate electricity from scavenging

\footnotetext{
*Corresponding author: e-mail: zheng@nanosys.mech.tohoku.ac.jp

**Corresponding author: e-mail: hiroki.kuwano@nanosys.mech.tohoku.ac.jp https://doi.org/10.18494/SAM.2020.2855
} 
on-site ambient vibrations. To achieve robust and highly efficient devices under harsh ambient vibrations at low frequencies, aluminum nitride (AIN)/stainless steel (SUS) heterolayered materials were proposed to be used for PVEHs. AlN films were successfully deposited on 304 stainless steel (SUS304) foils with a thickness of $50 \mu \mathrm{m}$ by electron cyclotron resonance (ECR) sputtering and reactive radio frequency (RF) magnetron sputtering. ${ }^{(3,4)}$

The lifetime of PVEHs strongly depends on their resistance to dynamic vibrations since they are exposed to cyclically dynamic stress during long-cycle vibration. Defects in both AIN and SUS materials may occur due to the vibration, resulting in a decrease in the output power of AIN/SUS-based PVEHs and finally causing their failure. Hence, investigation of the fatigue behavior of the materials is necessary for the design of PVEHs. Previous studies showed the effects of the manufacturing process and material form (bulk or film) on material properties of AlN. ${ }^{(5,6)}$ There has been no investigation on the fatigue of sputtered AlN films on flexible SUS430 foils although the fatigue of bulk AlN materials has been well studied. ${ }^{(7,8)}$ In addition, the downscaling of micro-PVEHs results in differences in mechanical properties between the macro- and microscales for both metallic and nonmetallic materials. ${ }^{(9-13)}$ Also, the fatigue behavior of materials with heterolayered structures is affected by the material-layer composition. $^{(14,15)}$ A previous study on the fatigue of $1-\mu \mathrm{m}$-thick AlN films deposited on both sides of a $50-\mu \mathrm{m}$-thick SUS304 foil showed that the fatigue limit of the materials in the AlN/ SUS304/A1N structure was higher than that of SUS304 foils. ${ }^{(15)}$ Recently, metal foils with a low coefficient of thermal expansion (CTE) close to that of piezoelectric films have become more attractive for use as structural materials for micro-PVEHs. SUS430 foils with a lower CTE than SUS304 and whose manufacturing can be scaled up as easily as SUS304 are the focus of our interest. Although the fatigue behaviors of SUS430 foils and $1 \mu \mathrm{m}$ AlN films deposited on SUS430 were studied, ${ }^{(16)}$ the fatigue property of the deposited AlN films is unknown when their thickness is increased.

In this work, we investigated the fatigue of SUS430 foils and foils with an AlN/SUS430/ AlN heterolayered structure for micro-PVEHs. In particular, the effect of AlN thickness on the fatigue behavior of the heterolayered materials was studied. AlN films with different thicknesses of 1 and $2 \mu \mathrm{m}$ were directly sputtered on 50 - $\mu \mathrm{m}$-thick SUS430 substrates. Cantilevers were microfabricated for the investigation. The Young's moduli of SUS430 and the sputtered AlN films were tested first. Then fatigue tests of SUS430 foils and AlN/SUS430/ AlN heterolayered materials were subsequently conducted by using a resonant fatigue testing system. ${ }^{(15,17,18)}$ The stress-number of cycle $(S-N)$ curves, fatigue limit, and fatigue failure are discussed in this paper.

\section{Experiment}

\subsection{Fabrication of specimens}

Cantilever specimens for fatigue tests were manufactured by microfabrication as shown in Fig. 1. ${ }^{(16)}$ The thickness of SUS430 foils was $50 \mu \mathrm{m}$. AlN films were deposited on both sides of a clean SUS430 substrate by alternative current magnetron reactive sputtering. ${ }^{(19)}$ Two types of heterolayered structure, AlN $(1 \mu \mathrm{m}) / \mathrm{SUS} 430(50 \mu \mathrm{m}) / \mathrm{AlN}(1 \mu \mathrm{m})$ and AIN $(2 \mu \mathrm{m}) / \mathrm{SUS} 430$ 


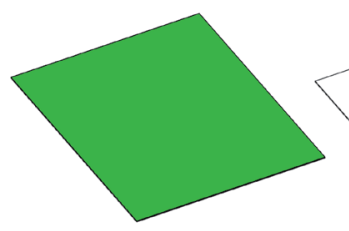

(a)

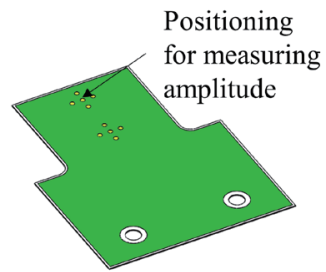

(d)

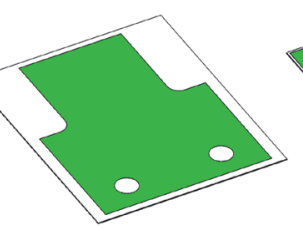

(b)

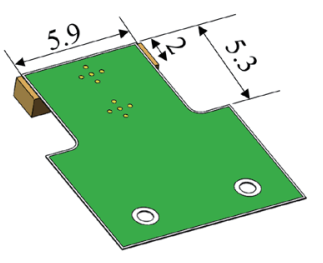

(e)

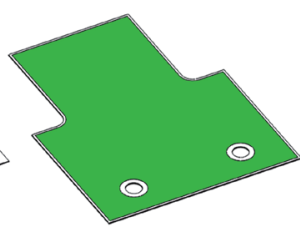

(c)

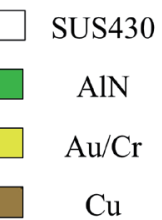

$\mathrm{Cu}$

Fig. 1. (Color online) Microfabrication of specimens: (a) cleaning SUS430 and depositing AIN films, (b) etching AlN films, (c) etching SUS430 foil, (d) depositing $\mathrm{Cr} / \mathrm{Au}$, and (e) adding proof mass. ${ }^{(16)}$

$(50 \mu \mathrm{m}) / \mathrm{AlN}(2 \mu \mathrm{m})$, were prepared. The thickness of the deposited AlN films was measured using a film thickness measuring device (Lambda A, Dainippon Screen MFG Co., Ltd., STM620J). The average thicknesses were 1.05 and $2.02 \mu \mathrm{m}$. Then, the films were wet-etched with tetramethylammonium hydroxide (TMAH $2.38 \%$ ) in the temperature range of $35-38{ }^{\circ} \mathrm{C}$ [Fig. 1(b)]. ${ }^{(15)}$ After the SUS430 substrate was micromachined to from the cantilever shape by electrochemical etching [Fig. 1(c)], ${ }^{(15,20)}$ chromium (Cr) and gold (Au) films were deposited on a cantilever specimen for positioning when measuring the amplitude of the specimen during fatigue tests [Fig. 1(d)]. Finally, the copper proof mass was added at the tip of the specimen [Fig. 1(e)]. The cantilever was designed to be $5.3 \mathrm{~mm}$ in length and $5.9 \mathrm{~mm}$ in width. The size of the proof mass was $2 \times 6 \mathrm{~mm}^{2}$, and two different thicknesses, 1 and $0.5 \mathrm{~mm}$, were used to tune the resonant frequencies of the cantilevers. Figure 2 shows images of the microfabricated specimens. The cantilevers were successfully micromachined without any defect at the edge.

\subsection{Experimental procedure}

The resonant fatigue testing system developed in a previous study ${ }^{(15)}$ was used. This system can detect the amplitude of the vibrating specimen by using a laser displacement sensor (Keyence, LK-H050). The resonant spectra in the 1st vibration mode of the SUS430 $(50 \mu \mathrm{m})$, AlN $(1 \mu \mathrm{m}) /$ SUS430 $(50 \mu \mathrm{m}) / \operatorname{AlN}(1 \mu \mathrm{m})$, and AlN $(2 \mu \mathrm{m}) / \operatorname{SUS} 430(50 \mu \mathrm{m}) / \mathrm{AlN}(2 \mu \mathrm{m})$ cantilevers without the proof mass were first tested by measuring the specimen amplitude varying with frequency. Three cantilevers were tested for each material to ensure the measurement repeatability. The Young's moduli of SUS430 foils were determined from its relationship with the resonant frequency as shown in Eq. (1) and then used for the calculation of the Young's moduli of the sputtered AlN films using Eq. (2). ${ }^{(15,16,21,22)}$ To improve the accuracy of the calculation, the actual length of each cantilever was measured under a microscope (Hirox KH-7700). Finally, fatigue tests were conducted by measuring the deflection of the micromachined cantilevers 


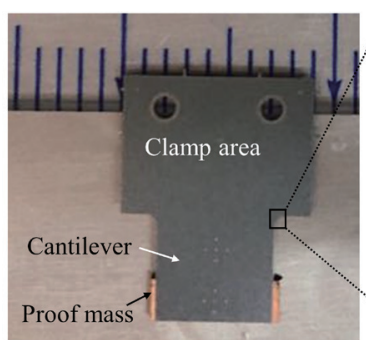

(a)

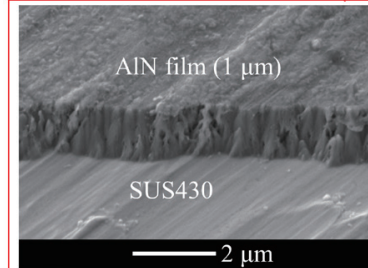

(c)

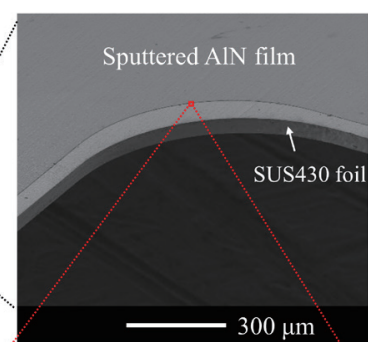

(b)

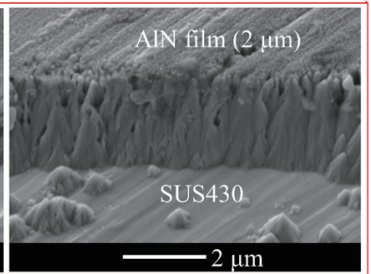

(d)

Fig. 2. (Color online) Images of microfabricated specimens: (a) overall image of cantilever, (b) enlarged image around the corner, and (c) and (d) enlarged images of etched AIN films with thicknesses of 1 and $2 \mu \mathrm{m}$. (a), (b), and (c) are cited from Ref. 16.

under cyclic vibrations. ${ }^{(17)}$ The fatigue of a material is discussed here on the basis of $S-N$ curves. The fatigue life was determined on the basis of a criterion proposed in a previous study. ${ }^{(15)}$ The stress distribution in the cantilevers was calculated by finite element analysis (FEA) using ANSYS Workbench 18.0. The obtained Young's moduli were input in the FEA. The maximum stress was used to plot $S-N$ curves. The details of FEA calculation and measurement were explained in the previous study. ${ }^{(15)}$

$$
\begin{gathered}
E_{S U S}=12 \rho_{S U S} \cdot \frac{4 \pi^{2} f_{n}^{2}}{\left(k_{n} L\right)^{4}} \cdot\left(\frac{L^{2}}{h_{S U S}}\right)^{2}, \\
E_{A I N}=\frac{12 \rho_{e q} \cdot \frac{4 \pi^{2} f_{n}^{2}}{\left(k_{n} L\right)^{4}} \cdot V L^{3}-E_{S U S} b h_{S U S}^{3}}{2 b h_{A l N}^{3}+6 b h_{A l N}\left(h_{S U S}+2 h_{A l N}\right)^{2}},
\end{gathered}
$$

where $E_{S U S}$ and $E_{A I N}$ are the Young's moduli of the SUS430 foil and sputtered AlN film, respectively; $f_{n}$ is the resonant frequency of the cantilever; $L$ is the length of the cantilever; $k_{n} \cdot L$ is the coefficient for a clamped-free boundary condition, under which $k_{1} \cdot L$ is equal to 1.875 in the 1 st vibration mode; $h_{S U S}$ and $h_{A l N}$ are the thicknesses of SUS layer and AlN layer, respectively; $\rho_{e q}$ is the equivalent density of the heterolayered AlN/SUS430/AlN structure; ${ }^{(23)} b$ is the width of the cantilever; and $V$ is the total volume of the cantilever. 


\section{Results and Discussion}

\subsection{Young's moduli of SUS430 foil and deposited AIN film}

Figure 3 shows the Young's moduli of the SUS430 foils and sputtered AIN films calculated using Eqs. (1) and (2). As shown in Table 1, the average Young's moduli are 207.7 and 305.6 GPa for the SUS430 foils and AlN films, respectively. Compared with the measured results for the SUS304 foils and AlN films deposited on SUS304 from the previous study, ${ }^{(15)}$ the average Young's modulus of SUS430 shows larger values while that of AlN films deposited

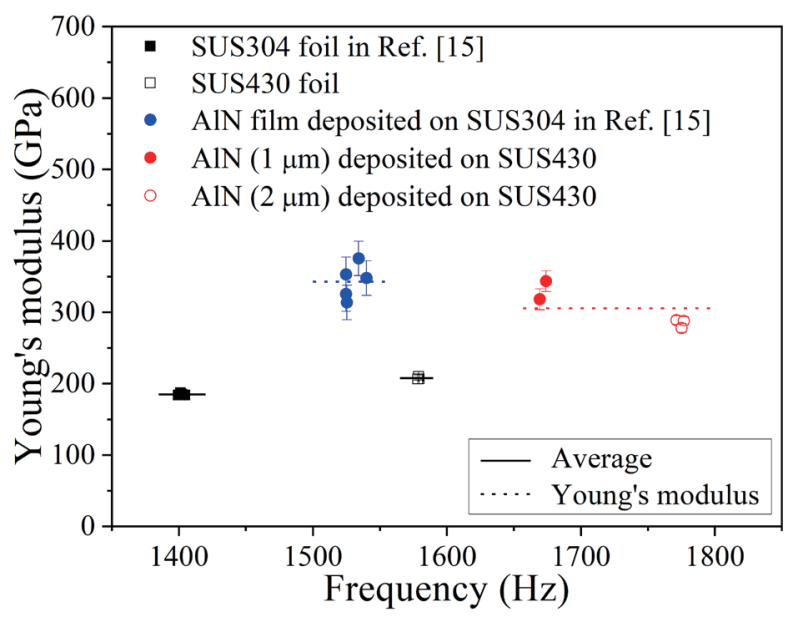

Fig. 3. (Color online) Young's moduli of SUS430 foils and AIN films deposited on SUS430, and comparison with those of SUS304 foils and AlN films deposited on SUS304 (from Ref. 15), in which Young's moduli of SUS430 and $1 \mu \mathrm{m}$ AlN deposited on SUS430 were taken from Ref. 16.

Table 1

Young's moduli of SUS, sputtered AlN films, and heterolayered AIN/SUS/AIN structure.

\begin{tabular}{|c|c|c|c|}
\hline Material & Density $\left(\mathrm{g} / \mathrm{cm}^{3}\right)$ & Young's modulus (GPa) & Bending stiffness $\left(\times 10^{-5} \mathrm{~N} \mathrm{~m}^{2}\right)$ \\
\hline SUS304 ${ }^{(\mathrm{a})}$ & $7.85 \pm 0.08$ & $184.9 \pm 1.2$ & 1.14 \\
\hline AlN $(1 \mu \mathrm{m})$ deposited on SUS304 ${ }^{(\mathrm{a})}$ & $3.26^{(24)}$ & $342.9 \pm 24.2$ & - \\
\hline AlN $(1 \mu \mathrm{m}) / \operatorname{SUS304/AIN~}(1 \mu \mathrm{m})^{(\mathrm{a})}$ & $7.68 \pm 0.08^{(\mathrm{b})}$ & $204.7 \pm 2.7^{(\mathrm{b})}$ & $1.41^{(\mathrm{b})}$ \\
\hline SUS $430^{(\mathrm{c})}$ & $7.63 \pm 0.08$ & $207.7 \pm 1.9$ & 1.15 \\
\hline AlN $(1 \mu \mathrm{m})$ deposited on SUS430 ${ }^{(\mathrm{c})}$ & $3.26^{(24)}$ & $326.4 \pm 14.6$ & - \\
\hline AlN $(2 \mu \mathrm{m})$ deposited on SUS430 & $3.26^{(24)}$ & $284.8 \pm 6.1$ & - \\
\hline AlN deposited on SUS430 ${ }^{(d)}$ & $3.26^{(24)}$ & $305.6 \pm 24.9$ & - \\
\hline $\operatorname{AlN}(1 \mu \mathrm{m}) / \operatorname{SUS} 430 / \operatorname{AlN}(1 \mu \mathrm{m})^{(\mathrm{c})}$ & $7.47 \pm 0.08^{(\mathrm{b})}$ & $223.7 \pm 1.7^{(\mathrm{b})}$ & $1.39^{(\mathrm{b})}$ \\
\hline AlN $(2 \mu \mathrm{m}) / \mathrm{SUS} 430 / \mathrm{AlN}(2 \mu \mathrm{m})$ & $7.32 \pm 0.08^{(b)}$ & $229.5 \pm 1.4^{(\mathrm{b})}$ & $1.60^{(\mathrm{b})}$ \\
\hline
\end{tabular}

${ }^{(a)}$ Corresponding values for SUS304 foils and AlN films deposited on SUS304, which are cited from Ref. 15.

(b) Equivalent value for heterolayered AlN/SUS/A1N structure.

${ }^{(c)}$ Cited from Ref. 16 .

(d) Average value of AIN (1 and $2 \mu \mathrm{m})$ deposited on SUS430. The density of SUS foils was measured using a balance scale (A\&D, GR-120). 
on SUS430 shows lower values. However, considering the error range, the Young's moduli of the AlN films deposited on both SUS430 and SUS304 show similar variations. Compared with that of the AlN film deposited on the silicon substrate by pulsed direct current reactive sputtering, ${ }^{(25)}$ the Young's moduli of the deposited AlN films in this study are lower.

To evaluate the resistance of the material against bending deformation, the bending stiffness ( $E I$, where $E$ is Young's modulus and $I$ is the second moment of the area) of each material is also shown in Table 1, in which the equivalent bending stiffness of the heterolayered AlN/SUS/AIN structure was calculated. ${ }^{(22)}$ As the thickness of the sputtered AlN films increases, the bending stiffness of the cantilever also increases. This is attributed to the stiffness of AlN being larger than that of SUS.

\subsection{Fatigue properties}

$S-N$ curves are first plotted to characterize the overall fatigue properties of the materials. Since no fracture occurred in all the fatigue tests, the approach described in detail in the previous study was used to determine the fatigue life and plot the $S-N$ curves. ${ }^{(15)}$ Then, the fatigue failure of the materials after long-cycle vibration is discussed.

\subsection{1 $S-N$ curves}

Figure 4(a) shows the $S-N$ curves of each material. Similar to the tendency of $S-N$ curves of SUS304 and AlN $(1 \mu \mathrm{m}) / \mathrm{SUS} 304 / \mathrm{AlN}(1 \mu \mathrm{m}),{ }^{(15)}$ the $S-N$ curve of SUS430 shows two stages, while that of AlN/SUS430/AlN shows three stages. The fatigue life of the heterolayered foils increases gradually with decreasing maximum stress when the applied maximum stress is relatively high $(350 \mathrm{MPa}$ in the case of $1 \mu \mathrm{m}$ AlN film and $450 \mathrm{MPa}$ in the case of $2 \mu \mathrm{m} \mathrm{AlN}$

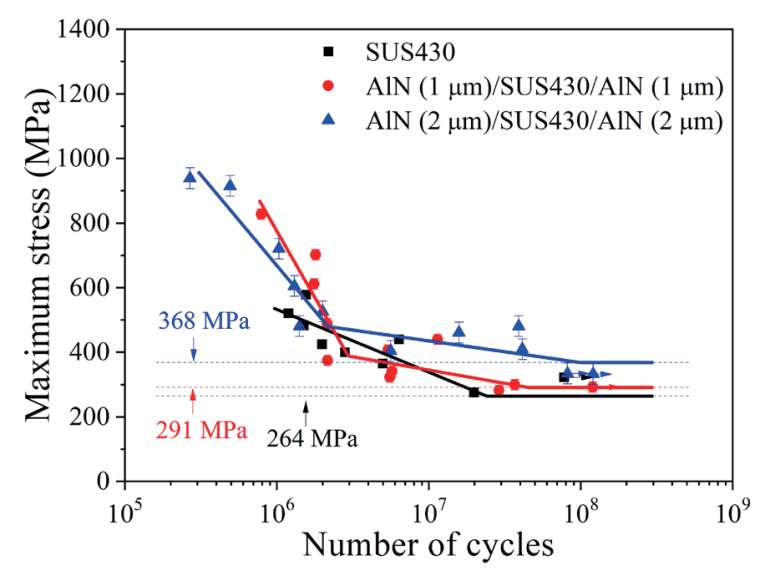

(a)

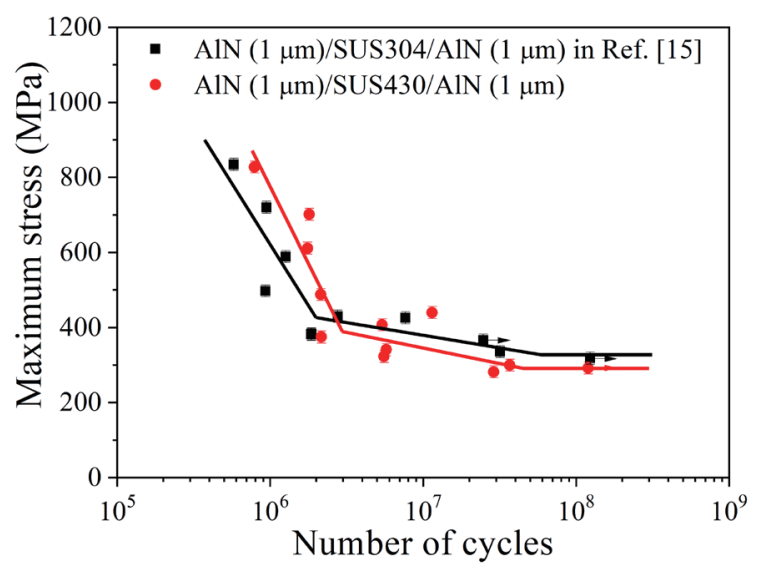

(b)

Fig. 4. (Color online) $S-N$ curves of (a) AlN/SUS430/AlN heterolayered foils with different thicknesses of AlN films $(0,1$, and $2 \mu \mathrm{m})$ and (b) comparison between AIN $(1 \mu \mathrm{m}) / \operatorname{SUS} 430 / \mathrm{AIN}(1 \mu \mathrm{m})$ and AlN $(1 \mu \mathrm{m}) / \mathrm{SUS} 304 /$ AlN $(1 \mu \mathrm{m}),{ }^{(15)}$ in which $S-N$ curves of SUS430 and AIN $(1 \mu \mathrm{m}) / \operatorname{SUS} 430 / \mathrm{AlN}(1 \mu \mathrm{m})$ are from Ref. 16. 
film on SUS430). Then, the fatigue life increases rapidly with decreasing stress. Finally, the fatigue life reaches more than $10^{8}$ cycles for all the three foils at a relatively low stress. At a stress higher than $450 \mathrm{MPa}$, the two heterolayered foils indicate similar fatigue lives. This is considered to be due to the large deformation caused by the large deflection of both materials. However, at a stress lower than $450 \mathrm{MPa}$, the fatigue life of the heterolayered foils increases with increasing thickness of AlN films owing to the increased foil stiffness (Table 1). The Basquin relationship was used to calculate the fatigue limit of SUS430, ${ }^{(26)}$ while the least-squares method was used to estimate the fatigue limit of the heterolayered materials. The fatigue limits of SUS430, AlN $(1 \mu \mathrm{m}) / \mathrm{SUS} 430 / \mathrm{AlN}(1 \mu \mathrm{m})$, and AlN $(2 \mu \mathrm{m}) / \mathrm{SUS} 430 / \mathrm{AlN}(2 \mu \mathrm{m})$ were estimated to be 264, 291, and $368 \mathrm{MPa}$, respectively, indicating an increasing tendency with increasing thickness of the deposited AlN films. This is considered to be attributed to the increased stiffness of the heterolayered foils with thicker AlN films. Similar results that thicker AlN films exhibit a higher fracture strength were obtained in the study in Ref. 25.

Figure 4(b) shows the $S-N$ curves of AlN $(1 \mu \mathrm{m}) / \operatorname{SUS} 430 / \mathrm{AlN}(1 \mu \mathrm{m})$ and AlN $(1 \mu \mathrm{m}) /$ SUS304/AlN $(1 \mu \mathrm{m})$. The fatigue life of AlN $(1 \mu \mathrm{m}) /$ SUS430/AlN $(1 \mu \mathrm{m})$ indicates its longer cycle than that of AlN $(1 \mu \mathrm{m}) / \mathrm{SUS304/AIN}(1 \mu \mathrm{m})$ when the maximum stress is higher than $400 \mathrm{MPa}$. When the applied stress decreases, the fatigue lives of these two materials become close to each other. This is considered to be due to the reduced amplitude of the cantilever at a lower stress. The large amplitude of the specimen at a higher stress causes a large deformation, while the small amplitude results in a small elastic deformation. Thus, the fatigue lives of these two heterolayered materials indicate a similar number of cycles at a stress lower than $400 \mathrm{MPa}$. Owing to the smaller bending stiffness of AIN $(1 \mu \mathrm{m}) / \operatorname{SUS} 430 / \mathrm{AlN}(1 \mu \mathrm{m})$ (Table 1), its fatigue limit is lower than that of AlN $(1 \mu \mathrm{m}) / \mathrm{SUS} 304 / \mathrm{AlN}(1 \mu \mathrm{m})$.

\subsubsection{Fatigue failure}

To evaluate the defect of the cantilevers after long-cycle vibration, surface changes were observed in the maximum-stress area [Fig. 5(a)] of the cantilevers. ${ }^{(15)}$ Figures 5(b) and 5(c) show images of SUS430 foils after fatigue tests at two different stress levels. The surface shows severer defects of intrusions when vibrating at $440 \mathrm{MPa}$ than when vibrating at $275 \mathrm{MPa}$. This is caused by the long-time plastic deformation when vibrating at a higher stress level.

Regarding the heterolayered materials, no surface defects were observed on AlN films after the fatigue tests at all stress levels up to $939 \mathrm{MPa}$. This is attributed to the high fracture strength of the sputtered AIN thin films. ${ }^{(25)}$ In addition, no fracture occurred in these films after suffering a maximum cyclic stress of $1.28 \mathrm{GPa}$ for $10^{4}$ cycles. ${ }^{(25)}$ However, surface defects were observed on the SUS430 layer. Figures 5(d) $-5(\mathrm{~g})$ show the defects observed on the heterolayered foils vibrating at different stress levels. Owing to the long-cycle vibration, the fatigue failure of cracks was observed on the surface of SUS430 in AIN $(1 \mu \mathrm{m}) / \mathrm{SUS} 430$ / AlN $(1 \mu \mathrm{m})$ when vibrating at the maximum stress of $488 \mathrm{MPa}$ for $2.9 \times 10^{7}$ cycles [Fig. 5(d)]. The faster initiation and propagation of intrusions inside the ductile material SUS430 are considered to be the reason for the occurrence of cracks. However, no cracks were observed for the long-cycle vibration at a lower stress of $292 \mathrm{MPa}$ as shown in Fig. 5(e). In addition, the 

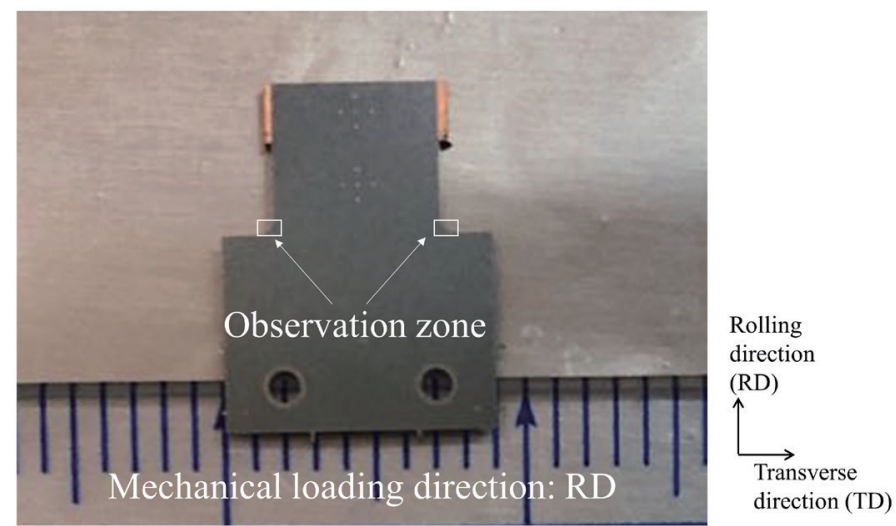

(a)

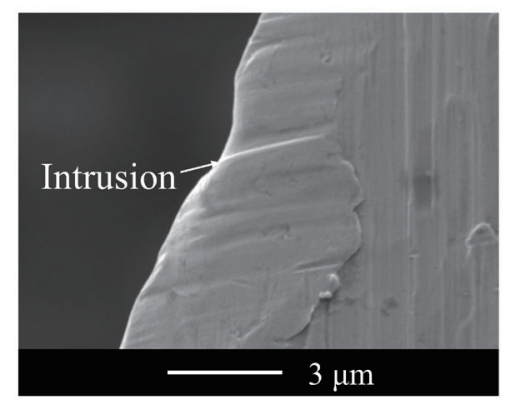

(b)

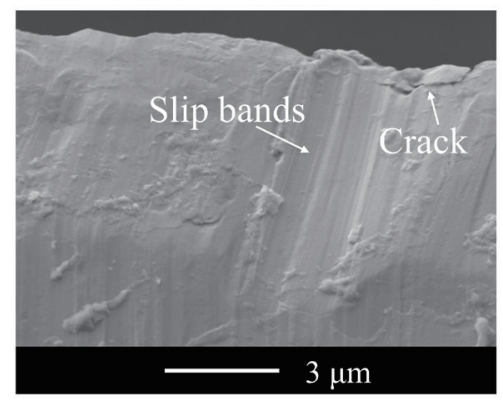

(d)

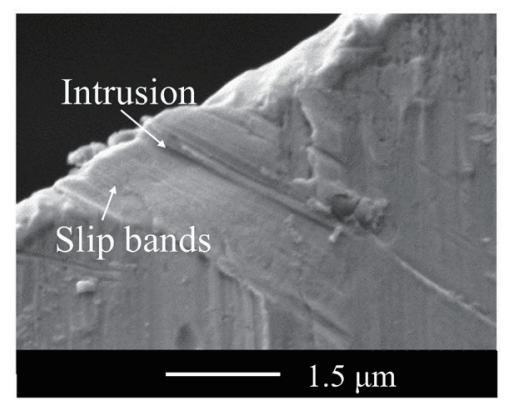

(d)

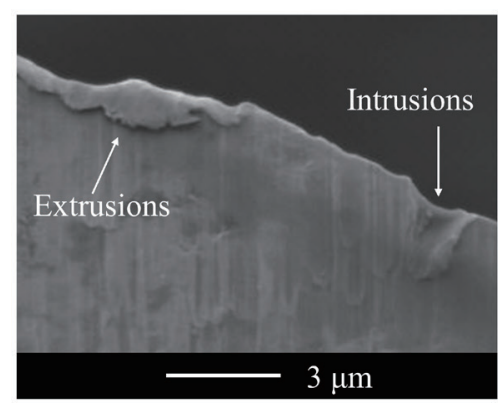

(c)

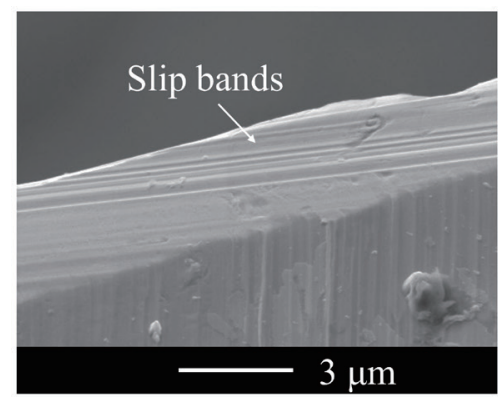

(e)

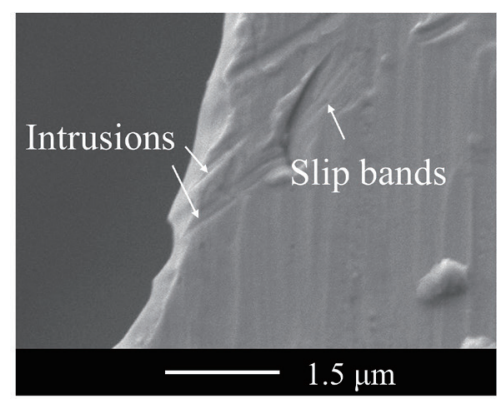

(e)

Fig. 5. (Color online) Fatigue failures on SUS430 surface: (a) image of observation zone and mechanical loading direction, (b) and (c) SUS430 after vibrating at the maximum stresses of $440 \mathrm{MPa}$ for $3.0 \times 10^{7}$ cycles and $275 \mathrm{MPa}$ for $1.5 \times 10^{8}$ cycles, (d) and (e) AlN $(1 \mu \mathrm{m}) / \mathrm{SUS} 430 / \mathrm{AlN}(1 \mu \mathrm{m})$ after vibrating at the maximum stresses of 488 MPa for $2.9 \times 10^{7}$ cycles and $292 \mathrm{MPa}$ for $1.2 \times 10^{8}$ cycles, and (f) and $(\mathrm{g})$ AlN $(2 \mu \mathrm{m}) / \mathrm{SUS} 430 / \mathrm{AlN}(2 \mu \mathrm{m})$ after vibrating at the maximum stresses of $605 \mathrm{MPa}$ for $2.9 \times 10^{7}$ cycles and $409 \mathrm{MPa}$ for $8.3 \times 10^{7}$ cycles, in which (c), (d), and (e) are cited from Ref. 16. 
SUS430 surface in AlN $(2 \mu \mathrm{m}) / \mathrm{SUS} 430 / \mathrm{AlN}(2 \mu \mathrm{m})$ also showed no cracks after the long-cycle vibration as shown in Figs. 5(f) and 5(g). In particular, for the same number of vibration cycles of $2.9 \times 10^{7}$ for AlN $(1 \mu \mathrm{m}) /$ SUS430/AlN $(1 \mu \mathrm{m})$ [Fig. 5(d)], the propagation of defects on the SUS430 surface of AlN $(2 \mu \mathrm{m}) / \mathrm{SUS} 430 / \mathrm{AlN}(2 \mu \mathrm{m})$ is slower even when the stress is higher. This is due to the larger stiffness (Table 1) of the foils with thicker AlN films. Although no cracks occurred, the surface defects in forms of intrusions and slip bands were observed owing to the strain localization that developed in this area. ${ }^{(15)}$

\section{Conclusions}

In this study, the fatigue behavior of micromachined specimens fabricated using SUS430 and AlN/SUS430/AlN heterolayered foils was studied as guide in the design of PVEHs. The effect of AlN film thickness on the fatigue behavior of AIN/SUS430/AlN heterolayered foils was also investigated.

AlN films with different thicknesses of 1 and $2 \mu \mathrm{m}$ were successfully sputtered on the SUS430 substrate with a thickness of $50 \mu \mathrm{m}$. Cantilever specimens were microfabricated for use in fatigue tests. The Young's moduli of the SUS430 foil and sputtered AlN film were determined to be 207.7 and $305.6 \mathrm{MPa}$, respectively. Fatigue was discussed here on the basis of $S-N$ curves and fatigue failures on the surfaces of the cantilevers. The fatigue limits of SUS430 $(50 \mu \mathrm{m}), \operatorname{AlN}(1 \mu \mathrm{m}) / \operatorname{SUS} 430(50 \mu \mathrm{m}) / \operatorname{AlN}(1 \mu \mathrm{m})$, and AlN $(2 \mu \mathrm{m}) / \operatorname{SUS} 430(50 \mu \mathrm{m}) /$ AlN $(2 \mu \mathrm{m})$ were estimated to be 264,291 , and $368 \mathrm{MPa}$, respectively. The fatigue limit shows an increasing tendency with increasing thickness of AlN films. Fatigue defects in forms of slip bands, intrusions and extrusions, and cracks were observed on the surface of SUS430, while no surface defects were found on AIN films. The fatigue failure of the heterolayered foils was confirmed to be caused by the failure of SUS430 substrates rather than AlN films.

\section{Acknowledgments}

This work was supported by the A-STEP project of JST (AS2815014R) and JKA Social Action Program.

\section{References}

1 S. Saadon and O. Sidek: Energ. Convers. Manage. 52 (2011) 500. https://doi.org/10.1016/j.enconman.2010.07.024

2 M. T. Todaro, F. Guido, V. Mastronardi, D. Desmaele, G. Epifani, L. Algieri, and M. D. Vittorio: Microelectron. Eng. 183 (2017) 23. https://doi.org/10.1016/j.mee.2017.10.005

3 Z. Cao, J. Zhang, and H. Kuwano: Sens. Actuators, A 179 (2012) 178. https://doi.org/10.1016/j.sna.2012.02.026

4 N. Moriwaki, L. V. Minh, R. Ohigashi, O. Shimada, H. Kitayoshi, and H. Kuwano: PowerMEMS 2016, J. Phys.: Conf. Series (2016) 012049. https://doi.org/10.1088/1742-6596/773/1/012049

5 Q. Li, Z. Wang, C. Wu, and X. Cheng: J. Alloy Compd. 640 (2015) 275. https://doi.org/10.1016/ j.jallcom.2015.03.235

6 A. Ababneha, U. Schmidb, J. Hernandoc, J. L. Sánchez-Rojasc, and H. Seidel: Mater. Sci. Eng., B 172 (2010) 253. https://doi.org/10.1016/j.mseb.2010.05.026

7 T. Kawakubo and A. Goto: J. Soc. Mater. Sci. Jpn. 36 (1987) 1253. https://doi.org/10.2472/jsms.36.1253

8 G. Subhash and G. Ravichandran: J. Mater. Sci. 33 (1998) 1933. https://doi.org/10.1023/A:1004325926287

9 U. Engel and R. Eckstein: J. Mater. Process. Tech. 125-126 (2002) 35. https://doi.org/10.1016/S09240136(02)00415-6 
10 F. Vollertsen, D. Biermann, H. N. Hansen, I. S. Jawahir, and K. Kuzman: CIRP Annals-Manuf. Technol. 58 (2009), 566. https://doi.org/10.1016/j.cirp.2009.09.002

11 G.P. Zhang, K. Takashima, M. Shimojo, and Y. Higo: Mater. Lett. 57 (2003) 1555. https://doi.org/10.1016/ S0167-577X(02)01023-6

12 G.P. Zhang, K. Takashima, and Y. Higo: Mater. Sci. Eng., A 426 (2006) 95. https://doi.org/10.1016/ j.msea.2006.03.090

13 X. Zhang, C. Zhao, T. Yao, S. Zhou, J. Han, J. Li, T. Gao, X. Wang, K. Zheng, and B. Song: Nanotechnology 28 (2017) 275703. https://doi.org/10.1088/1361-6528/aa73e7

14 X. Yan, M. Kato, and K. Nakasa: J. Soc. Mater. Sci. Jpn. 50 (2001) 1335. https://doi.org/10.2472/jsms.50.1335

15 Q. Zheng, L. Van Minh, and H. Kuwano: Sens. Actuators, A 285 (2019) 173. https://doi.org/10.1016/ j.sna.2018.11.022

16 Q. Zheng, L. Van Minh, N. H. Hung, and H. Kuwano: PowerMEMS 2019 (accepted).

17 K. Kwak, M. Otsu, and K. Takashima: Sens. Mater. 22 (2010) 51. https://doi.org/10.18494/SAM.2010.627

18 Y. Shimizu, L. V. Minh, H. Kitayoshi, and H. Kuwano: PowerMEMS 2016, J. Phys.: Conf. Series 773 (2016) 012116. https://doi.org/10.1088/1742-6596/773/1/012116

19 L. V. Minh and H. Kuwano: IEEE 30th Int. Conf. Micro Electro Mechanical Systems (2017) 833. https://doi. org/10.1109/MEMSYS.2017.7863537

20 T. Takahashi, L. Van Minh, K. Umeda, T. Fuji, and H. Kuwano: PowerMEMS 2017. https://doi. org/10.1088/1742-6596/1052/1/012039

21 Y. Y. Kim: Measurement 115 (2018) 133. https://doi.org/10.1016/j.measurement.2017.10.029

22 J. Gryzagoridis, G. Oliver, and D. Findeis: Insight 57 (2015) 140. https://doi.org/10.1784/insi.2014.57.3.140

23 A. Khan, J. Philip, and P. Hess: J. Appl. Phys. 95 (2004) 1667. https://doi.org/10.1063/1.1638886

24 R. Andosca, T. G. McDonald, V. Genova, S. Rosenberg, J. Keating, C. Benedixen, and J. Wu: Sens. Actuators, A 178 (2012) 76. https://doi.org/10.1016/j.sna.2012.02.028

25 E. Österlund, J. Kinnunen, V. Rontu, A. Torkkeli, and M. Paulasto-Krockel: J. Alloy. Comp. 772 (2019) 306. https://doi.org/10.1016/j.jallcom.2018.09.062

26 E. Santecchia, A. M. S. Hamouda, F. Musharavati, E. Zalnezhad, M. Cabibbo, M. El Mehtedi, and S. Spigarelli: Adv. Mater. Sci. Eng. 2016 (2016) 9573524. https://doi.org/10.1155/2016/9573524

\section{About the Authors}

Qiu Zheng received her B.S. and M.S. degrees in materials processing engineering from Huazhong University of Science and Technology, China, in 2010 and 2013, respectively, and her Ph.D. degree in human mechatronics systems from Tokyo Metropolitan University, Japan, in 2015. She joined Hitachi, Ltd. as a researcher in 2015 and worked as a researcher of New Industry Creation Hatchery Center, Tohoku University, Japan from 2017 to 2019. She is currently a researcher in the Department of Mechanical and Biofunctional Systems, Institute of Industrial Science, The University of Tokyo, Japan. Her research interests are in materials processing, microforming, and microfabrication. (zheng@nanosys.mech.tohoku.ac.jp)

Le Van Minh was born in Thanh Hoa, Vietnam, in 1983. He received his B.S. degree in engineering physics and his M.Sc. degree in materials science from Hanoi University of Science and Technology, Vietnam, in 2006, and 2008, respectively, and his Ph.D. degree in nanomechanics from Tohoku University, Sendai, Japan, in 2013. From 2013 to 2015, he was a research fellow of Tohoku University, Japan. Since 2015, he has been an assistant professor of Tohoku University. His current research interests are in nano/microfabrication, nano/ microenergy systems, lead-free piezoelectric materials, and polymer electrets.

(minhlv@nanosys.mech.tohoku.ac.jp) 
Hoang Hung Nguyen received his diploma in engineering physics from Hanoi University of Science and Technology, Vietnam, in 2010, and Ph.D. degree in nanomechanics from Tohoku University, Japan, in 2018. He is currently a postdoctoral fellow in the New Industry Creation Hatchery Center (NICHe), Tohoku University, Japan. His research activities are focused on high-performance energy harvesters, especially lead-free-based vibration energy harvesters. (hung@nanosys.mech.tohoku.ac.jp)

Hiroki Kuwano received his B.Eng. and M.Eng. degrees in mechanical engineering and his Ph.D. degree in electrical engineering from Tohoku University, Sendai, Japan, in 1975, 1977, and 1990, respectively. He was a member of Electrical Communication Laboratories of Nippon Telephone and Telegraph Public Corporation. Since 2003, he has been a professor of Tohoku University. He has authored or co-authored over 120 technical papers and books, and over 50 patents in microelectromechanical systems and particle beam processing. His research interests are in nanoenergy systems, including energy harvesting systems and sensor networks, particularly, those used for safety and medical applications.

(hiroki.kuwano@nanosys.mech.tohoku.ac.jp) 